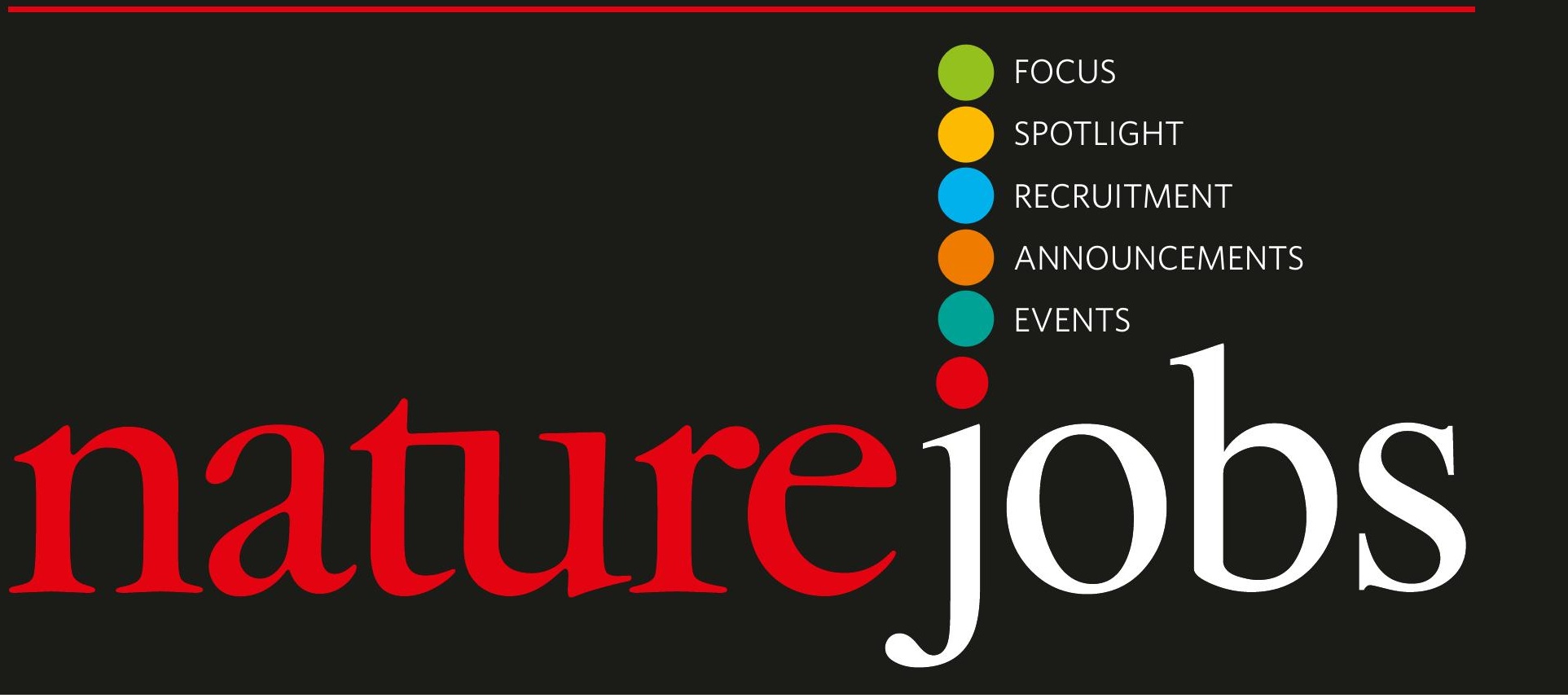

\title{
Searching questions
}

During the Internet boom of the mid-1990s, information technology (IT) researchers could practically write their own ticket. Then the bubble burst, and many IT experts found themselves scanning the 'help wanted' adverts. Although the halcyon days are history, demand for IT experts may once more be on the rise, this time from search-engine companies such as Yahoo and Google.

Last month, both firms made aggressive moves to attract top talent from computer giants IBM, Apple and Microsoft, and there are signs of more to come. Yahoo recruited Prabhakar Raghavan, who helped IBM develop a search technology called 'Clever', and another senior IBM technology researcher Andrew Tomkins. It also took on Apple's Larry Tessler in a bid to help the company become more user friendly. Google, meanwhile, attracted Kai-Fu Lee from Microsoft to help it build a laboratory in China.

Such moves don't come without some retribution. Microsoft warned Lee that he may be in violation of a 'no-compete' clause in his contract, because he has key knowledge about Microsoft technology that is still in

CONTACTS

Publisher: Ben Crowe

Editor: Paul Smaglik

Marketing Manager: David Bowen

US Head Office, New York

345 Park Avenue South, 10th Floor,

New York, NY 10010-1707

Tel: +1 8009897718

Fax: +18009897103

e-mail: naturejobs@natureny.com

US Sales Manager/Corporations: Peter Bless

Classified Sales Representatives

Tel: +18009897718
New York/Pennsylvania/ Latin America: Kelly Roman Midwest USA/Maryland/ NIH: Wade Tucker

East USA/Canada:

Janine Taormina

San Francisco Office

Classified Sales Representative:

Michaela Bjorkman

West USA/West Corp. Canada

225 Bush Street, Suite 1453

San Francisco, CA 94104

Tel: +14157813803

Fax: +14157813805

e-mail:m.bjorkman@naturesf.com

the works. And the former IBM employees now at Yahoo have said they need to tread carefully around intellectualproperty laws.

Although these moves are notable for their high-profile nature, questions remain over whether IT jobs as a whole will recover, or whether this is just a quick flurry of activity limited to a few senior positions at a few companies. Will Apple, Microsoft and IBM fight back by hiring more searchengine scientists? Will Google and Yahoo expand their teams further, creating even more opportunities for IT experts? And will smaller search companies enter into the hiring fray?

Whatever the outcome, researchers looking for employment in the field should temper their optimism with caution, lest their bubble burst again.

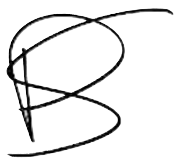

\section{Paul Smaglik, Naturejobs editor}

European Head Office, London

The Macmillan Building,

4 Crinan Street,

London N19XW, UK

Tel: +44 (0) 2078434961

Fax: +44 (0) 2078434996

e-mail:naturejobs@nature.com

Naturejobs Sales Director: Nevin Bayoumi (4978) European Sales Manager: Andy Douglas (4975)

Advertising Production Manager: Billie Franklin To send materials use London address above. Tel: +44 (0) 2078434814

Fax: +44 (0) 2078434996

e-mail: naturejobs@nature.com
Naturejobs web development: Tom Hancock Naturejobs online production: Niamh Shields

European Satellite Office

Patrick Phelan

e-mail:p.phelan@nature.com

Japan Head Office, Tokyo

Chiyoda Building,

2-37 Ichigayatamachi,

Shinjuku-ku,

Tokyo 162-0843

Tel: +81332678751

Fax: +81332678746

Asia-Pacific Sales Director: Rinoko Asami

e-mail: r.asami@naturejpn.com 